\title{
English Language in the Development of a Tolerant Person of the Student in a Multi-Ethnic Educational Environment of the University (For Example, Kazan Federal University)
}

\author{
Rezida A. Fahrutdinova ${ }^{1}$ \\ ${ }^{1}$ Institute of Philology and Intercultural Communication, Kazan (Volga Region) Federal University, Kazan, \\ Russia \\ Correspondence: Rezida Akhatovna Fahrutdinova, Institute of Philology and Intercultural Communication, \\ Kazan (Volga Region) Federal University, Kazan, Russia. Tel: 007-960-046-6937. E-mail: fahrutdinova@list.ru
}

Received: September 15, 2014 Accepted: October 27, 2014 Online Published: November 19, 2014

doi:10.5539/elt.v7n12p77 URL: http://dx.doi.org/10.5539/elt.v7n12p77

\begin{abstract}
Integration into the world community confronts the Russian education system purpose - education of the individual, having planetary thinking, able to see themselves not only as the representative of the native culture, living in a particular country, but also a citizen of the world, perceiving himself as the carrier and its foreign-language cultures. An important component of the socio-political development of multicultural education is the desire of both Russia and other countries integrate into the global European socio-cultural and educational space, while retaining their national identity. These processes contribute to the transformation of both Europe and Russia as a multilingual space where different languages have equal rights.

There is an urgent social need for the organization of purposeful work on the formation of a tolerant person of the student, the system combines knowledge of different cultures, the desire and the willingness to intercultural Polylog. This era of social order urgently requires development of the younger generation of universal values, acculturation of other nations, which increases the motivation to learn foreign languages, associated with the desire to establish and develop contacts with foreign countries. It is English as a language of international communication acts as the major means to realize this idea in a multi-ethnic educational environment of the university. The article presents the results of a study conducted at the Kazan Federal University.
\end{abstract}

Keywords: tolerance, multiethnic environment, multiculturalism, culture, international communication, English, foreign language culture

\section{Introduction}

Multicultural society feels the need for a new outlook, aimed at the integration of cultures and peoples with a view to further convergence and spiritual enrichment. All this proves the importance of multicultural education, the purpose of which stands the formation of human culture, a creative personality, capable of active and productive life in a multicultural environment.

Integration into the world community determines before the Russian education system need to educate a person having planetary thinking, able to see themselves not only as the representative of the native culture, living in a particular country, but also a citizen of the world, perceiving himself as the carrier and its foreign-language cultures. Hence there is an objective need for the formation of a tolerant person of the student in the higher education system. Multiculturalism of the Russian Federation, which is determined on a territorial basis, requires understanding the problems of inter-ethnic relations, tolerance and cultural dialogic. Multi-ethnic environment, which is characterized by a diversity of cultures, requires the formation of the student's personality, capable of manifestation of tolerance of views and judgments, recognition and promotion of cultural pluralism and the freedom to choose their own cultural identity. As part of establishing a tolerant person of the student, it is important utilization of the English language and elements of folk pedagogy that create favorable conditions for their initiation to the spiritual values that form the human and national dignity, as well as contribute to the acculturation of the individual in the national culture within the framework of a multi-ethnic society.

Thus, the need for a study of this problem is dictated by the prevailing contradictions between: 
- Objectively increasing needs of society in the formation of tolerant person in a multicultural education and the insufficient development of the content, forms and methods of its organization in the educational process of high school;

- The available capacity of the discipline "Foreign Language" in the formation of a tolerant person of the student and the insufficient development of evidence-based pedagogical conditions for its implementation.

The need to develop multicultural competence of students and the lack of scientific and methodological support this process in a multi-ethnic environment of the university, which involves interaction with people of different nationalities, the knowledge of their cultural traditions and customs, which ultimately promotes dialogue and interaction between different ethnic cultures and a culture of interethnic communication.

Formation of tolerant person is focused on the process of instilling respect and understanding student uniqueness of other people, the diversity of their cultures and historical features. This is a manifestation of the aggregate of such personal qualities of the student as: tolerance, harmony, balance, soundness of judgment, "reconciliation" of polar and non-compatible components and relationships that occur both in learning and cognitive activity (classroom and extracurricular), and in the sphere of interpersonal communication in the subject-subject relations. As part of the implementation of this idea are the following tasks: formation of students' perceptions of multicultural education and a positive attitude to their cultural differences; development and skills of effective interaction with students from different cultures; deep and comprehensive mastery of the students the culture of his people as a precondition for integration into other cultures; education of students in the spirit of tolerance and humane international communication.

Analysis of the scientific literature on the research showed that many local teachers (A. G. Asmolov, B. S. Gershunsky, D. V. Zinoviev, and others.) Suggest the formation of a new direction in pedagogy - pedagogy of tolerance. According to them, it should do the following problems: the creation of social and educational conditions tolerant interaction tolerant educational-educational space; the creation of conditions of culture of dialogue; development of synergistic thinking, allowing to take a wide range of personality traits, individual and ethnic manifestations of human etc.; student-centered approach in the educational process, the basis of which are the subject-subject relations in the "teacher-student" (Mishchenko, 1993).

The main conditions for the formation of tolerance teachers are called as follows: increase the awareness of students about the essential and meaningful characteristics of tolerance, especially his study in the various fields of knowledge, especially of a foreign language; development of tolerance in the field of values of students and the transformation of tolerance in the regulatory principle of their professional and non-professional activities; formation and skills tolerant interpersonal interaction; the formation of attitudes of tolerance, which consists in the ability and emotional-readiness of the student to an equal dialogue with other partners in the understanding of the friendly communication; Use of lecture, discussion and game forms and training in educational work for the formation of tolerance.

The basis of the formation of tolerance based on the following principles:

- The rejection of violence as an acceptable means of familiarizing the person to any idea. Free choice, "freedom of conscience," the emphasis on sincerity of belief. Just as in Christianity, "preaching and example" are ways of proselytizing, the idea of tolerance may become a landmark uniting like-minded people;

- The ability to force myself not forcing others. Fear and coercion from the outside do not contribute to the formation of tolerance, although as an educational factor at some point people discipline, thereby generating some manners;

- Tolerance, in the European sense, sets the example of the "law-abiding", obey the laws, traditions and customs. Obedience to laws, and not the will of the majority or of one person, it is an important factor in social development;

- Acceptance of the other, which may be different on different grounds - national, racial, cultural, religious, etc. Forming relationships according to the "golden" rule: "Do unto others as you would have them do unto you but" (Menskaya, 1993).

Teaching tolerance is multidimensional. Among the specific objectives of its education in the framework of our university are the following: a deep and comprehensive mastery of the students the culture of his people as a precondition for integration into other cultures; formation of students' ideas about multiculturalism, parenting positive attitude towards cultural differences, contributing to the progress of mankind and employees prerequisite for self-development; facilitating the integration of students in other cultures; the formation and development of skills of effective interaction with different cultures; education of students in the spirit of 
tolerance, human inter-ethnic communication.

As part of the theoretical basis of this research problem are the following types of tolerance:

- Interpersonal tolerance - the ability and practical recognition of other values, logic thinking and behavior;

- Mezhsotsialnaya tolerance - aimed at ensuring a sustainable harmony between different social groups;

- Interfaith tolerance - tolerance for others' beliefs;

- Ethnic or intercultural tolerance - the interest and attention to the thoughts, opinions, experiences, customs, behavior of other cultures, ethnicities, nationalities (Archangelsky, 1976).

Considering the problem of the formation of tolerance among university students, it is appropriate to apply to a number of psychological and sociological researches, in which stand out the specific features of the Russian mentality. For example, Academician A. M. Novikov, referring to the peculiarities of the Russian mentality, highlights the "unusually great kindness, humane world, when in the first place in the system of human values are the fate of all mankind, in the background - the fate of his people, and the third - the fate of his family, his own destiny". The author also notes the quality, close tolerance to the "Russian citizen has no equal when it is necessary to lift very heavy, or suffer intolerable when it is necessary to dissolve their lives in other people's lives or to devote themselves to the cause". In this case especially, the author notes "openness, curiosity Russians, the ability of the Russian culture open to outside influences, to absorb the values of different peoples, spiritually enriched and convert them, while maintaining their uniqueness and unity" (Nikolaeva, 1998).

Thus, all of the above, combined with the negative, is particularly pronounced in the last decade and a half (as in the social life of Russia as a whole, and in high school educational environment), allows us to justify the idea of the need for further work on the problem of formation of tolerance among students in a multiethnic educational environment of the university (Bashieva \& Gelyaeva, 2003).

In the Russian Federation multicultural education meets the needs of multi-ethnic population, namely, the people of Russia, while maintaining the leading role of Russian culture, are simultaneously different types of civilized and therefore in need of a variety of models of education. Therefore, as a priority policy of the state can be identified the need for a tolerant coexistence of the majority population of ethnic and national minorities.

Consequently, multicultural education is seen as a process of assimilation of ethnic personality, national and world culture, its spiritual enrichment and development of the planetary world, the formation of readiness and ability to live in a multi-ethnic environment.

In this case, defining the idea of multicultural education is the possibility of coexistence of many different sub-cultures of the region. Considering the features of the development of multicultural education in our region, it must be emphasized that the Republic of Tatarstan is one of the central places in the Eurasian region, is the point of intersection, interaction and mutual influence of Eastern and Western cultures, different language groups and traditions, religions and civilizations.

The peculiarity of our country are the multi-ethnicity and poly-confessional population, the development of which is characterized by a close mutual influence and interpenetration of ethno-cultural traditions of the peoples living on the territory of modern Tatarstan. Determines the position in this process is held by representatives of the Tatar and Russian peoples, who constitute the majority in relation to the members of all other nations. Suffice it to note that, according to the National Census in 2010 in Tatarstan, home to more than 80 nationalities (including the Tatars-53.2\%, Russian-39.7\% and 7.1\% of other nations) (Baryshnikov, 2002).

All this determines the specific mission of the republic in the life not only of the multinational and multicultural Volga-Ural region and the country, as well as the entire Eurasian region, the successful development of versatile and strong ties between Russia and the countries of Asia, strengthening mutual understanding between European and Asian countries. Hence, the most important aspect of the educational activities of the Institute of Philology and Intercultural Communication is the development of scientific, educational and cultural base for establishing a relationship of trust and cooperation, consensus and partnership between different peoples and nations of the East and West, based on the historical experience of peaceful coexistence Russian, Tatar and other peoples residing in the Republic of Tatarstan.

Creating a culture-medium in the higher education system contributes to the humanistic conception of education, which is recognized under the intrinsic value of the individual student and the need to create the most favorable conditions for its self as the subject of the pedagogical process. In this case, the implementation of student-centered learning is impossible without constructing internal culture-medium education and the education of the individual student. 
Integration into the world community requires consideration of national traditions in the education and training of students; creation of conditions for the formation of their cultural identity, and the creation of diverse and complex cultural environment for the development of the individual student. Therefore, the projection to the realities of the Russian reality of the educational system rise complex tasks such as preparing the younger generation for life in the new environment of multinational and multicultural environment, the formation of the ability to communicate and cooperate with people of different nationalities, races and religions.

In our research we consider the multicultural space of the university as a social and educational environment of formation of cross-cultural social and educational relationships between the students who contribute to the creation of national culture and human values based on the mastery of educational content in areas of training for a variety of undergraduate majors and graduate programs.

Thus, multicultural educational environment is a social and educational environment of formation of a tolerant person of the student, in which are cross-cultural social and educational relationships that promote internalization of national culture and the formation of human values.

\section{Literature Review}

Of particular interest in this issue are part of the study, reflected in article of Rezeda Failevna Mukhametshina and Alfiua Foatovna Galimullina carried out on the material of the Republic of Tatarstan Inculcation of Bimental Personality in Context of Cultural Dialogue (As Exemplified by Tatarstan Schools). These authors note "Analysis of the results of interview has shown that principle of cultural dialogue is implemented in school where native Tatar language is taught with the same rate as Russian while in Russian schools the students tend to mono-culture. Performed by us analysis allows concluding that dialogue of cultures in education system determines formation of bicultural potential of personality triggering genesis of bimental world view" (Mukhametshina \& Galimullina, 2014).

In a research conducted on the basis of Kazan Federal University authors Milyausha Muchametsyanovna Khabutdinova and Larisa Bayanova in article "Norms and Values Characteristics of Students in a Foreign Cultural Environment" notes that "The results of study allow stating that learning in a foreign culture environment save differences of norms and values. It speaks for acculturization in a students' environment along the lines of integration when each group keeps and saves its own culture and at the same time tends to maintain contacts with the representatives of different culture." These works are based on regional material and this is their practical value (Khabutdinova \& Bayanova, 2013).

Despite the numerous studies on the issue of tolerance and inter-ethnic communication, it is not enough work on the use of a foreign language as a means of forming a tolerant person of the student. Given these contradictions, we formulated the topic of research.

\section{Methods}

In this research, we conducted an experimental work at the Institute of Philology and Intercultural Communication of Kazan Federal University. To solve the problems and test assumptions study we used the following set of methods: theoretical (the study and analysis of the scientific literature on the issue of research, systems analysis study of concepts); diagnostic (observation, survey, interview, questionnaires, interviews, testing, self-esteem, monographic method for studying whole experience, analysis of the results of academic and extracurricular activities of students, ranging, expert interviews); experimental; pedagogical modeling; methods of mathematical statistics and others.

\section{Studying the Question}

\subsection{Intercultural Approach to English Language Teaching}

The growing interest in the educational and socializing huge potential of English as the international led to the emergence and development of a new direction - the language of multicultural education. That multicultural education student by means of the English language plays an important role in the process of their development, education and cultural self-determination (Rogers, 1984). Based on the thematic content of training programs and manuals in English, as well as the methods and forms of its feed material is modeling multicultural environment - the formation of the students' about the world and their place in it. Multicultural approach to the selection of learning content allows to draw attention to the possibility of acculturation of different ethnic and social groups in the country the language is spoken. Knowledge of the variability of crops contribute to the formation of students' perceptions of multicultural coexistence as the norm. As the P.V. Sysoev, a foreign language is one of the main instruments of educating people in a multicultural society. Means the target language can foster students' social competence, including the formation of such qualities as tolerance, patience, fairness 
to the representatives of other countries and cultures (Slastenin, 1994).

Considering the English language as a tool for development of tolerant qualities of the student in a multicultural educational environment of the university, highlighted the socio-cultural competence, contributing to the formation of such qualities as tolerance, patience, fairness to the representatives of other countries and cultures (Bashieva \& Gelyaeva, 2003).

That multicultural education of students by means of English allows students to see themselves as equal members of the world community, united by common interests and problems. That English is the possibility of acculturation of different ethnic, social, religious and other groups in the country the language is spoken. Knowledge of the variability of crops contributes to the formation of students' perceptions of multiculturalism as a norm of coexistence and prepares them for an active and full cooperation in the modern multicultural world.

\subsection{Experimental Study on the Formation of Personality Traits for Student Tolerant Interaction with Other Cultures}

However, analysis of the traditional language of university training programs shows that they are difficult to evaluate the criterion of multiculturalism for the following reasons:

1) In these programs are not well represented elements of the culture of the native language, which prevents involve students to foreign language culture and the formation of planetary thinking means foreign language;

2) The content does not reflect the principle of "dialogue of cultures", which prevents the integration of the individual in a multicultural educational environment and awareness of the values of national and world culture in terms of understanding the relationship of cooperation between cultures;

3) They have not received the full reflection of the issues of formation of tolerance towards people of different faiths and positive interaction with other cultures, particularly in relation to conflicts in intercultural interaction.

English also serves as an important means of familiarizing students to the spiritual culture of the peoples and nationalities. This gives students the opportunity to self-knowledge and self-expression within the framework of foreign language communication. This is facilitated by the study of authentic texts, reading fiction, newspapers and magazines in a foreign language, listening texts on listening, watching movies, the use of the Internet resources.

These tools enable students to identify similarities and differences in cultural diversity, different eyes to look at the problems of youth in the country of the target language, to get acquainted with the mentality, traditions and customs, way of life of the people of the country the language is spoken.

Last decades are characterized by significant changes in the objectives and content of teaching English both abroad and in Russia. It is, accordingly, require fundamental changes in the teaching of foreign languages in vocational training.

As the problems of identity formation in a multicultural student space of the university are the following: the integration of the individual in national and world culture, its identification with other cultures; developing skills of productive interaction with carriers of other cultures; familiarizing the student to the culture through education; The development of respect for the native language, culture and history of his people, the formation of the right of national identity; formation that rejects all forms of nationalism and chauvinism.

To identify the level of formation in students the qualities needed for tolerant interaction with others, namely the assessment of conflict (conflict-free) in the behavior of students, their level of empathy behavior, cultural identity and the existence of representations of cultural diversity, we conducted a survey.

Based on the survey questions (for Pluzhnik) Identify the level of tolerant behavior of students. Analysis of the data revealed that the lack of conflict among students is low (25\%), and conflict-high (75\%). The findings suggest that the instability of the manifestations of conflict-tolerant behavior of students and their ability to interact with a partner when discussing controversial issues. This suggests that students are facing serious difficulties in the process of communication with representatives of other cultures, which is manifested in a sense of fear, anxiety and even xenophobia. From the analysis of the students' answers can be seen that most of the subjects of aggression explosions are more destructive than constructive. They relate to others and their contemptuous behavior provokes conflict (Pluzhnik, 2003).

In accordance with the questionnaire (Yusupov, Nikireev), we had found the degree of tolerance for the expression of empathy students in their interpersonal interactions. The results confirmed the high degree of anxiety and uncertainty (54\%) of students in the process of communication with the representatives of other cultures. Proof of this is also indicators such as: the ability to understand the person with whom you 
communicate only-26\%; ability to explain behavior other- $22 \%$; feel confident in dealing with others-30\%.

The following questionnaire allowed us to determine whether students is an important own national culture, the extent to which they associate themselves with their own culture in the process of communication with the representatives of other cultures. Moreover, the degree of identification with the student's native culture determines the degree of his expectations from the representatives of other cultures norms and rules of behavior of their native culture. Analysis of indicators confirmed that belonging to the native culture is important for students (73\%), although 58\% of the students said they did not feel part of their nation. We believe that this fact is indicative of the lack of formation of the students' national identity and significant values of its people.

On the basis of the following questionnaire (Pluzhnik), we have determined the ability of students to identify the presence of similarities and differences in the native and other cultures. This allows you to properly understand the behavior of the different culture that plays an important part in the selection of tolerant behavior. The analysis showed that students are aware of the similarities and differences between the native and other cultures, but they can not define more precisely their boundaries $(21 \%)$. Therefore we can say that students insufficient socio-cultural competence to see the differences in native and other cultures.

Thus, the analysis of the results showed that the level of development of the student's personal qualities needed for tolerant interaction with the representatives of other cultures is quite low (Figure 1).

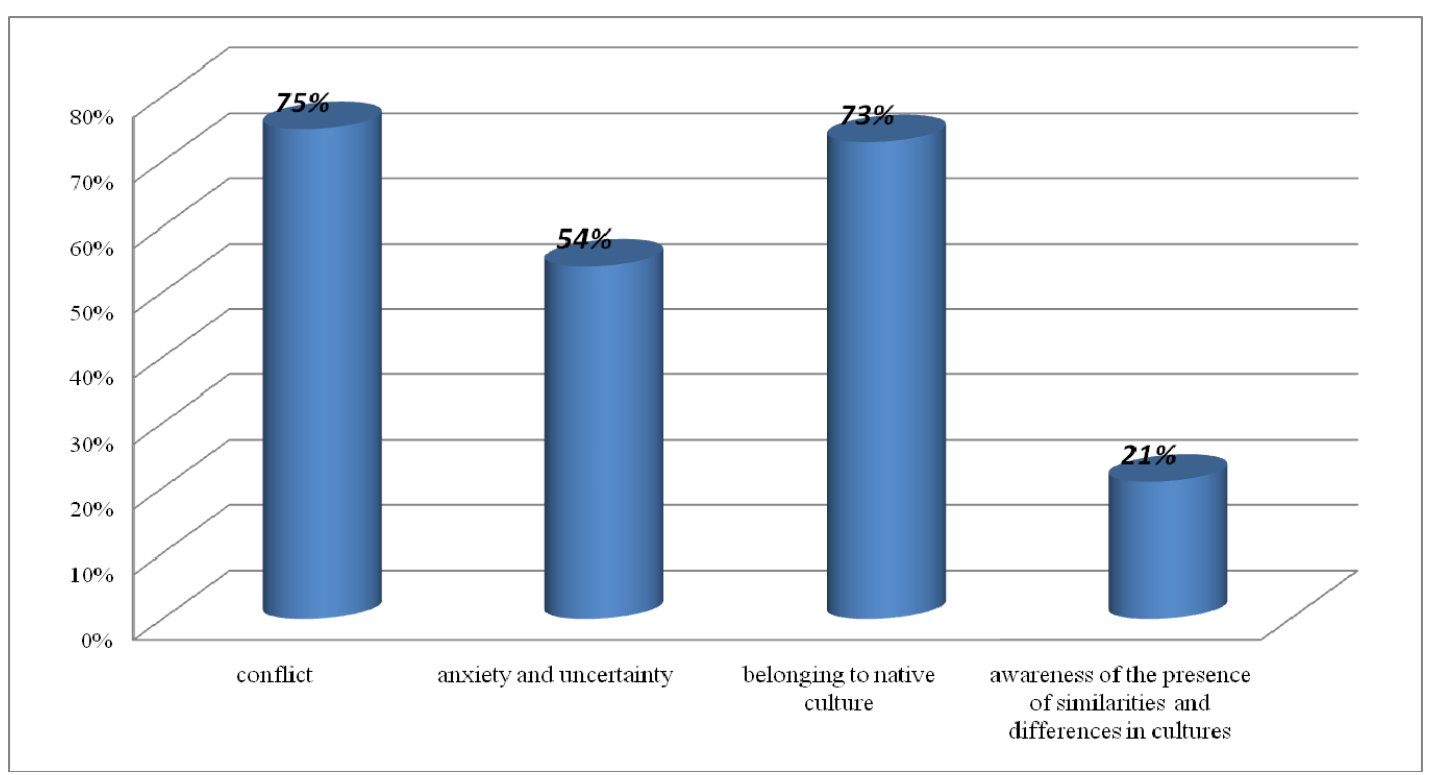

Figure 1. Results of the study the level of formation of the student personality traits for tolerant interaction with other cultures

In the course of experimental work we have been allocated such criteria as: cognitive, operational—the activity and motivation of values. The main methods of studying the level of formation of tolerance among students according to these criteria were testing, modeling of pedagogical situations, observation, interviews and self-assessment on the basis of reflection. The diagnostic results showed that the level of development of the cognitive, operational — the activity and motivational-value criteria is low.

\section{Conclusions}

\subsection{Scientific Novelty of the Research}

- Definition of pedagogical conditions of formation of a tolerant person of the student by means of English language in a multicultural multiethnic space of the university:

- Providing motivational involvement of students in the curriculum and extracurricular activities as subjects of intercultural communication;

- Identification of the educational potential of the English language and the definition of the forms and methods of its implementation; 
- Design model for the formation of a tolerant person of the student by means of English language in a multicultural, multi-ethnic space of the university;

- The structuring and implementation of content on the subject of "English" is based on the interaction of cultural variation value-target, communicative and organizational, program and strategic units to integrate the individual in a multicultural professional environment;

- Carried out the modeling process of gradual formation of a tolerant person of the student by means of English language in a multicultural, multi-ethnic space of the university, which includes the following components: goals, objectives; principles (multicultural and multiethnic affirmations, the implementation of subject-subject interaction, dialog learning, cultural reflection and variability); function multicultural environment of the university (adaptation, socio-legal, cultural, socio-educational, educational); meaningful units (value-target, communicative and organizational, program and strategic); organizational forms, methods, means of instruction; steps (motivational informing, diagnostic and corrective directing that determines synthesis) and the result of testing on selected criteria;

- Identified the possibility of forming a tolerant person of the student in a foreign pedagogy in a multicultural education, which can be used to improve the national education system: interactive (activity-concept and the concept of multiperspective education); socio-psychological (the concept of anti-racist education, the concept of "cultural differences", the concept of social learning); learning from other cultures (Teaching the Exceptional and Culturally Different); human relations; study of a particular group (Single-Group Studies); multicultural education; multicultural and social restructuring of education (Education that is Multicultural and Social Reconstructionist), etc.;

- Defined criteria and tolerance levels of the development of students in the study of the English language: cognitive, motivational and evaluative and operational-activity.

\subsection{The Theoretical Significance of the Research}

- Clarified the essential characteristics of the formation of a tolerant person of the student by means of English language in a multicultural multiethnic space of the university: cultural pluralism (monocultural, multicultural and intercultural education); culture of interethnic communication and personal identification in a multicultural society; theory of multicultural education, bilingual education; types, models, forms, factors, principles and objectives of the formation of tolerance, social and cultural tolerance; factors and conditions tolerant environment; multicultural educational environment and its components; regional specificity of multicultural educational environment of the university; linguistic multicultural education;

- Revealed principles of tolerant personality: multicultural and multiethnic affirmations dialog learning, cultural variation and reflection;

- Contained in the study of theoretical principles and findings contribute to the deepening of conceptual ideas about the formation of tolerance as the quality of the future specialist in the higher education system in terms of its reform;

- Introduced into scientific circulation original primary sources of foreign researchers to build a tolerant person of the student by means of a foreign language in a multicultural environment of the university.

\subsection{The Practical Significance of the Research}

- Results of the study enrich and expand the understanding of the essence of the process of formation of a tolerant person of the student in the educational process of high school by means of English language;

- Theoretical principles of research can serve as a scientific and methodological basis for the development of evidence-based recommendations for high school teachers to improve the training and purposeful formation of tolerance among students in a multi-ethnic space of the university.

\subsection{Conclusions}

Thus, the experimental results confirmed the accuracy of the hypothesis of the study. Figures obtained allowed us to develop a program to implement the integrated content items linguistic, methodological and general pedagogical training of students to build qualities of tolerance in multicultural space of the university.

The formation as a tolerant person of the student in a multicultural environment of the university involves mastery of knowledge about the similarities and differences between cultures, the development of new mental and emotional consciousness, including the presence of positive attitudes on interpersonal communication and teamwork, self-confidence, respect and tolerance for the interests, customs and traditions of other nations on the 
basis of the dialogue of cultures.

To solve this problem, higher education institution in need of a deeper methodological and theoretical and practical justification of multicultural environment of the university, which is designed to ensure that every student, regardless of nationality, social background and family traditions, equal opportunities for development in the wider social and cultural context, contribute to the formation human values and education of the citizen of the World.

\section{Acknowledgements}

The work is performed according to the Russian Government Program of Competitive Growth of Kazan Federal University.

\section{References}

Archangelsky, S. I. (1976). Lectures on the organization of the educational process in higher education. Moscow: High School.

Baryshnikov, N. V. (2002). Learning parameters of intercultural communication in the secondary school. Foreign languages at school, 7, 28-32.

Bashieva, S., \& Gelyaeva, A. (2003). Tolerance and the norm as the basis of the aesthetic vision of the world. Herald of the "Age of Tolerance", 6, 90-98.

Khabutdinova, M., \& Bayanova, L. (2013). Norms and Values Characteristics of Students in a Foreign Cultural Environment. Middle-East Journal of Scientific Research, 16(11), 1527-1531. http://dx.doi.org/10.5829/ idosi.mejsr.2013.16.11.12041

Menskaya, T. B. (1993). Multicultural education: Programs and methods. Society and education in the modern world. The collection of materials from foreign experience, 2, 37-40.

Mishchenko, A. I. (1993). Pedagogical process as the whole phenomenon. Moscow: Science.

Mukhametshina, R. F., \& Galimullina, A. F. (2014). Inculcation of Bimental Personality in Context of Cultural Dialogue (As Exemplified by Tatarstan Schools). Middle-East Journal of Scientific Research, 20(12), 2135-2138. http://dx.doi.org/10.5829/idosi.mejsr.2014.20.12.21108

Nikolaeva, V. A. (1998). Theory and methods of formation of pedagogical culture of the teacher (Unpublished doctoral dissertation). Moscow, Russian Federation.

Pluzhnik, I. L. (2003). Formation of the intercultural communicative competence of students in the humanities course of vocational training teacher (Unpublished doctoral dissertation). Tyumen, Russian Federation.

Rogers, K. (1984). Empathy. Psychology of emotion, 235-237.

Slastenin, V. A. (1994). Humanist paradigm of teacher education. Master, 6, 3-8.

\section{Copyrights}

Copyright for this article is retained by the author(s), with first publication rights granted to the journal.

This is an open-access article distributed under the terms and conditions of the Creative Commons Attribution license (http://creativecommons.org/licenses/by/3.0/). 